\title{
Quarry wall stability and design optimisation using photogrammetric mapping and analysis techniques
}

\author{
P.W. Booth Golder Associates Pty Ltd, Australia \\ G.E. Meyer Golder Associates Pty Ltd, Australia
}

\begin{abstract}
A geotechnical assessment of the Oaklands Junction Quarry, Melbourne was undertaken to provide recommendations on pit wall design parameters for use in future quarry planning. Holcim (Australia) Pty Ltd plans to double the depth of the existing main pit over the remaining life of the quarry, and a robust geotechnical assessment of the existing pit walls was required to provide long term pit face stability during operation and subsequent quarry rehabilitation.
\end{abstract}

Due to safety restrictions, access to the batters to undertake conventional (tape measure and compass) geotechnical mapping was very limited. The acquisition of geotechnical mapping data is described, using photogrammetric methods to undertake the mapping remotely. Measurements included the orientation, spacing, persistence and large scale waviness of the rock discontinuities that control the stability of the quarry pit walls.

The use of photogrammetry provided far greater mapping coverage and a much larger set of high quality geotechnical data than could have been obtained by conventional mapping methods. The persistence and large scale waviness of the discontinuities are critical to the geotechnical design, due to the typically low shear strength of joint infill materials.

The acquisition of high resolution digital terrain models (DTMs) of the quarry batter faces is described, generated using the 3DM Analyst Mine Mapping Suite (ADAM Technology, 2013) digital photogrammetry system from 'stereo pairs' of photographs taken of the pit walls. The same software was then used to carry out the remote geotechnical mapping. The results included more than 1,200 individual measurements of discontinuity orientation, as well as a smaller number of measurements of discontinuity spacing and persistence.

The DTMs were used to quantitatively assess the large scale waviness of selected discontinuities, and provided justification to increase the large scale friction angle adopted for the subsequent stability analyses by up to $5^{\circ}$, as compared to the values that would otherwise have been adopted based on drill core alone. The assessment of safe pit slope angles is discussed, and observations of existing large scale failures in the pit walls were used to corroborate the use of increased friction angle in the design.

\section{Introduction}

Holcim (Australia) Pty Ltd (Holcim) is currently planning the long term operation of the Oaklands Junction Quarry. The Oaklands Junction Quarry is located to the northwest of Melbourne, Australia, approximately $5 \mathrm{~km}$ north of Melbourne's Tullamarine airport (Figure 1). The future operations will involve approximately doubling the depth of the existing main pit over the remaining life of the quarry. To assist in future operations planning, Golder Associates Pty Ltd (Golder) was commissioned by Holcim to undertake a geotechnical assessment of the existing northern and western walls of the pit.

A geotechnical assessment of the existing pit walls was required to allow design of the final finished configuration of the upper slopes of the northern and western walls. The basis of the assessment was the existing conceptual design of the final rehabilitated pit upper slopes, detailed in the quarry work plan, which is approved by the relevant government regulatory authority (approved work plan). 
The acquisition of geotechnical mapping and drilling data was required to provide a basis for the geotechnical assessment.

Geotechnical mapping of the current pit walls presented a challenge due to restrictions on access, with site safety rules stipulating an exclusion zone adjacent to all cut batters. As a result, the use of conventional (tape measure and compass) geotechnical mapping methods to collect the data was not possible. Terrestrial photogrammetric methods were therefore employed to undertake the mapping remotely, using the 3DM Analyst Mine Mapping Suite software (ADAM Technology, 2013). The use of this method also provided several additional benefits over conventional mapping, including greater mapping coverage of otherwise inaccessible batters and the ability to quantitatively assess defect persistence, spacing and large-scale waviness.

Two boreholes were drilled by Holcim behind the northern wall for resource assessment purposes. Observations of defect frequency, roughness and infill material from the boreholes were also used to assist in the geotechnical assessment.

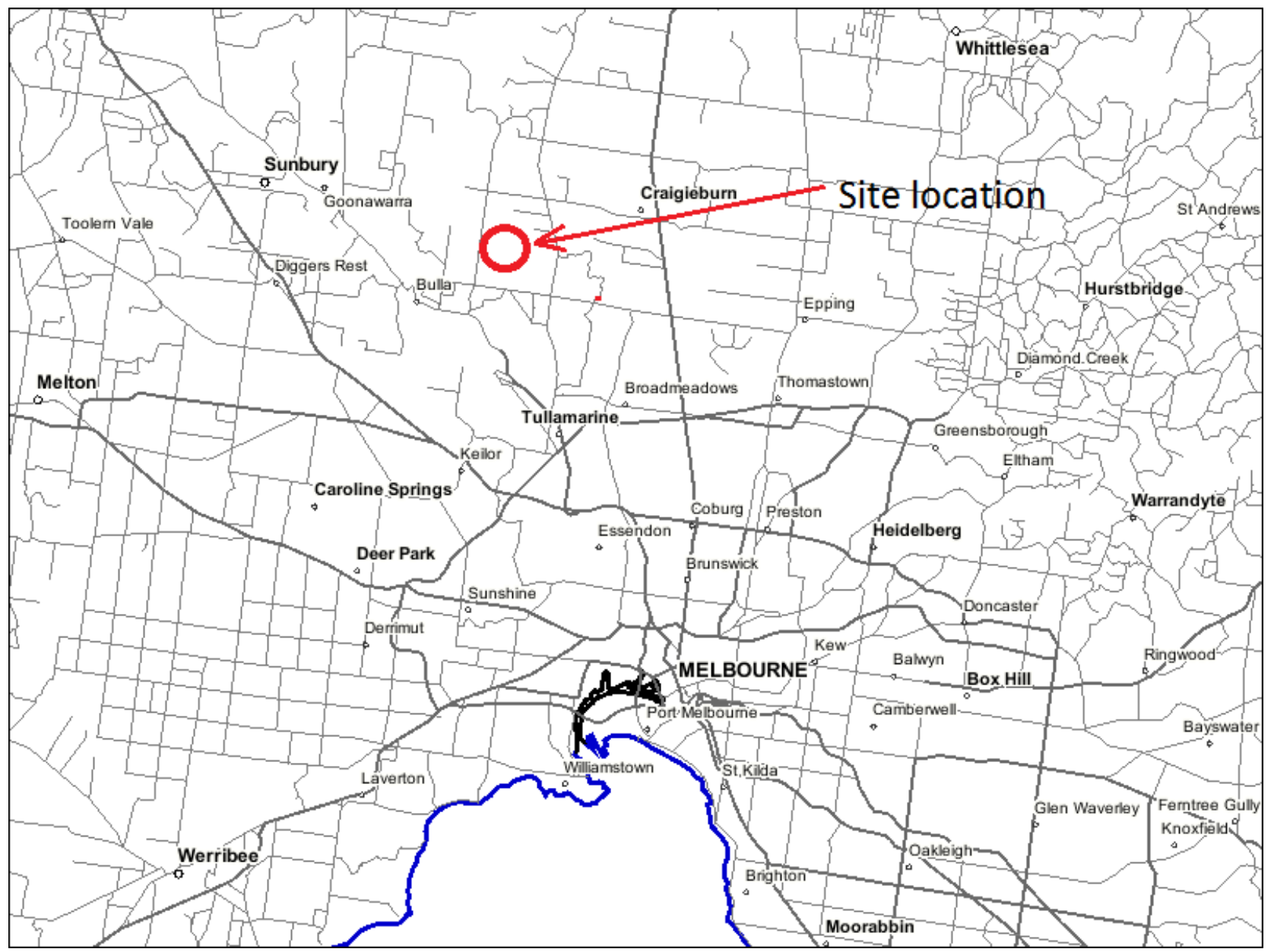

Figure 1 Site location (map courtesy of Geological Survey of Victoria (2013))

\section{Planned quarry development}

Holcim plans to more than double the depth of the pit in the long term. The current pit extends approximately $60 \mathrm{~m}$ below the natural surface level. The walls of the pit currently include 10 metre high batters, and benches of between 10 and $30 \mathrm{~m}$ width. The western boundary of the current pit is located in its terminal position, whereas the northern boundary of the current pit is located between 25 and $60 \mathrm{~m}$ from its final position. The final upper pit slope design contained in the approved work plan included a bench width to batter height ratio of approximately 1:1, with batter angles open to assessment. 


\section{Geology and rock mass structure}

The geology of the quarry's main pit comprises the Devonian-aged Bulla Granodiorite in the southern half and hornfels in the northern half (Figure 2). Both rock types are extracted from the main pit. The contact between the two rock types trends approximately east-northeast and west-southwest across the centre of the pit, turning towards the southwest in the western part of the pit. The hornfels has formed from contact metamorphism of the Silurian-aged Keilor Group sedimentary sequence by the Bulla Granodiorite. The Keilor Group includes shale, mudstone, greywacke and conglomerate. As is typical of the Silurian-aged sedimentary rocks underlying central Victoria, the sedimentary sequence has large scale tight folding trending approximately north-northwest and south-southwest. The limbs of the folds can be dipping up to sub-vertically, with limb faulting regularly occurring. The hornfels has retained the structure of the sedimentary parent rock, featuring relatively thin relict bedding structure generally dipping sub-vertically to the west. The exact lithology of the parent rock is difficult to determine due to the effects of metamorphism.

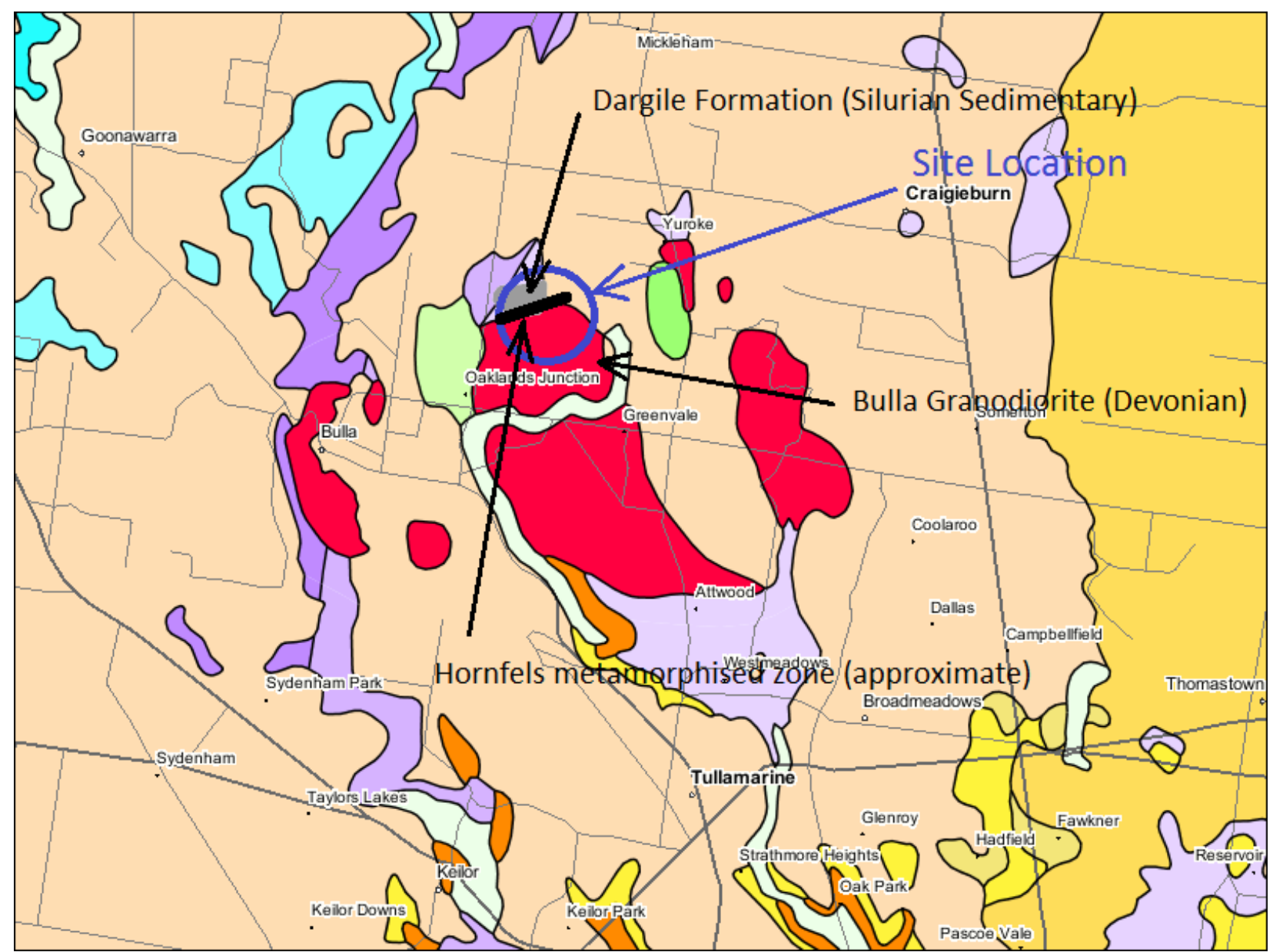

Figure 2 Geological map (courtesy of Geological Survey of Victoria (2013))

Both the granite and the hornfels were observed in the pit walls and borehole rock core to be relatively closely fractured, with fracture spacing observed in the rock core generally being less than $0.3 \mathrm{~m}$ (Figure 3). Major defect sets, as well as prominent isolated defects, were observed in the granite and hornfels. The defect sets in the hornfels in the northern and western walls of the main pit were assessed as part of the study. 


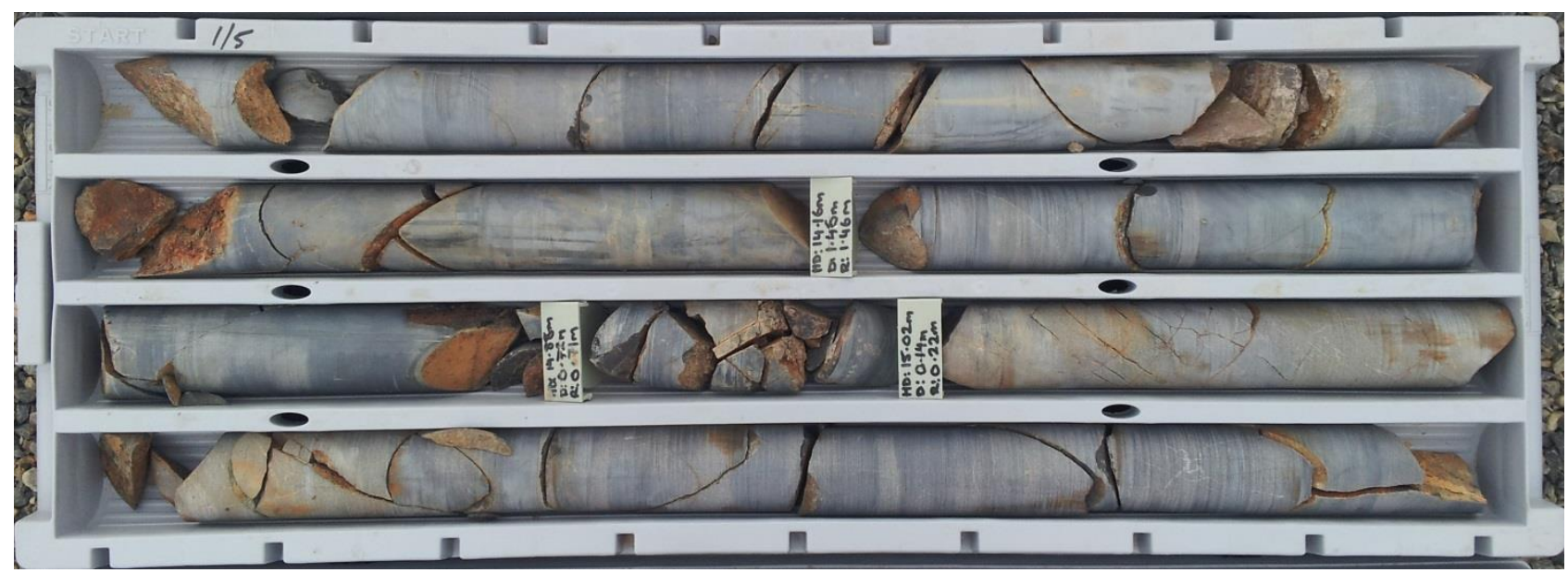

Figure 3 Photo showing typical core recovered from boreholes. Note smooth, planar defects at core diameter scale

Assessment of the relationship between the defect sets and the stress history of the area was not part of the study.

\section{$4 \quad$ Photogrammetric geotechnical mapping}

\subsection{Principals and applications of modern digital photogrammetry}

Digital photogrammetry is the science of determining the three-dimensional (3D) locations of objects from two-dimensional (2D) digital photographs. It has been referred to as the fourth cycle in the history of photogrammetry's development; being preceded by plane table photogrammetry (1850-1900), analogue photogrammetry (1900-1960), and analytical photogrammetry (1960-1990s); (Spring, 2012).

Digital photogrammetry uses digital photographs of a scene captured from two or more different locations (i.e. 'stereo pairs'), in the same way the human eye does, in order to perceive depth and dimension of space. By locating common points in both images (or groups of images), modern photogrammetric software can automatically calculate the 3D location of a very large number of points in the scene and use this information to automatically generate a digital terrain model (DTM). When coupled with the known (surveyed) location of a small number of control points in the scene (and/or known camera station locations), the DTM can be georeferenced and the user is able to digitise and measure features that can be seen in at least two images; to an accuracy of around 1:10,000 of the size of the area covered by a single image (ADAM Technology, 2010).

Some specific applications for the quarrying, mining and civil geotechnical industries include:

- Remote geological and geotechnical mapping.

- Remote mapping and survey of inaccessible and unsafe areas.

- Aerial topographic survey, using either conventional aircraft or unmanned aerial vehicles (UAVs).

- Slope stability and slope failure assessments and monitoring.

- Volume measurement (of excavations and stockpiles for example).

- Thickness measurement of shotcrete or other material layers.

- Convergence monitoring.

When correctly applied to the task of geotechnical mapping of jointed rock masses, digital photogrammetry can provide quality data sets in relation to some of the key parameters required for input to slope stability 
analyses, including: defect orientation, persistence, spacing, large scale waviness and 'real world' location; block size; and geotechnical character and spatial relationships of large scale geological structures.

A key limitation of long-range digital photogrammetry for geotechnical mapping (such as was used for the current study) is that it cannot provide measurements of certain other key defect characteristics, including: infill material type; infill thickness (or aperture); joint wall strength, and small scale roughness. However, small scale roughness can be measured to sub-millimetre accuracy, if required, by using close-range photogrammetry techniques.

\subsubsection{Alternative methods of remote geotechnical mapping}

For the specific task of remote geotechnical mapping of jointed rock masses, the primary alternatives to the 3DM Analyst system include:

- Other commercially available photogrammetry-based mapping packages such as Sirovision (CEA Mining Australia, 2013) and 3G Shape Metrix (3G Software and Measurement, 2013).

- Laser-based mapping systems such as I-Site (Maptek, 2013a).

In relation to other photogrammetry based systems; while there are some differences in the associated data collection and processing procedures, speed and (to a lesser extent) accuracy; the various different systems will all deliver essentially the same geotechnical mapping information.

When it comes to a comparison between photogrammetry-based and laser-based systems for this application, the different methods used by these two techniques result in differences in accuracy, range, speed and cost. Day (2010) summarised some of the basic differences between the two technologies as follows:

- Each point in a laser scanner point cloud is an independent sample, while the pixels in an image have a fixed relationship with respect to each other. So, you can georeference photogrammetric data using a small number of known points, confident that the rest of the data will be correct relative to those points; you can never be sure the same is true for scanned data.

- When it comes to range, photogrammetry gives a great deal of flexibility to the user, e.g. changing to a lens with double the focal length allows an image to be captured from twice as far away with very little effect on the results.

- Accuracy of 3D data for a DSLR depends on the relationship between lens focal length and distance, and the base to distance ratio. The user is free to operate from whatever distance is most convenient, simply choosing the lens and ratio to fit the accuracy requirements of the job. Unlike laser scanners, planimetric accuracy is typically more accurate than the depth accuracy (usually other way around for laser scanners).

- Range using a DSLR surpasses that of a scanner and can be more accurate.

These differences, along with the lower establishment cost for photogrammetric systems (software and camera equipment) as compared with laser systems (scanner and software), are considered by the authors as being significant advantages of the photogrammetry systems for the present application.

\section{$4.2 \quad$ Fieldwork}

Prior to undertaking the fieldwork (i.e. photography and ground control survey) for a photogrammetry project, careful planning is required to ensure that the data collected meets the stated requirements of the project, with maximum efficiency.

Some of the key questions that need to be asked prior to undertaking the planning include:

1. What is the required spatial accuracy for the project? 
2. What is the required DTM density? That is, what frequency of measured points is needed on the surface being modelled?

3. What is the required image resolution to allow the features of interest to be clearly seen in the images?

4. What restrictions or opportunities are there on where the camera can be positioned to take the photos?

5. What times of day will the photography be undertaken, and how does this relate to slope aspect? Good lighting of the subject slopes is critical to image quality.

Depending on the particular needs of a project and the conditions on site, one or more of these factors may dominate the planning process.

Accuracy and DTM density are discussed in more detail below. This discussion is based partly on training material provided by ADAM Technology and partly on the experience of the first author.

\subsubsection{Accuracy and DTM density planning}

Definition of the required spatial accuracy and DTM density are critical in the planning stage, as both of these factors strongly influence the approach taken to the data collection and the time required for processing of the data.

There are three main factors that influence the spatial accuracy of the data obtained, including:

1. The 'base to distance ratio', which is the ratio of the distance between camera station locations (the base) to the distance from the camera stations to the subject feature. This ratio is the primary factor controlling the 'distance accuracy' (i.e. the accuracy in the direction perpendicular to the plane of the camera's image sensor), and also strongly influences the 'plan accuracy' (i.e. the accuracy in the plane of the camera's image sensor).

2. The accuracy of the registration of the $3 D$ data into the project coordinate system (i.e. the georeferencing accuracy). This depends mainly on the geometry and accuracy of the surveyed ground control points.

3. The ground pixel size, which is the area on the ground covered by one pixel in the image. This is determined by the focal length of the lens used, the resolution of the camera's image sensor, and the distance of the camera from the subject feature. It affects both the plan and distance accuracy of the model, and also strongly influences the DTM density.

In addition to ground pixel size, other factors influencing the DTM density include:

1. Surface texture, or variation in pattern and/or colour in the scene, allows image correlation to recognise common points in stereo pairs of images and the subsequent generation of DTM points.

2. Image quality issues such as blur, poor lighting, shadow, and incorrect exposure all have a detrimental effect on image correlation and therefore DTM density and spatial accuracy.

\subsubsection{Accuracy and DTM density requirements}

Since the primary purpose of the mapping at the Oaklands Junction quarry was to measure the orientation, dimensions and shape of defect planes within the rock mass, accuracy and DTM density requirements for the project could be described as follows:

1. The spatial accuracy of the DTMs needed to be adequate to accurately orientate the models, so that the orientations of defect planes could be measured to within a few degrees of the actual orientations.

It was not necessary to very accurately measure the absolute $(x, y, z)$ location of the mapped defects in space, since they had only to be placed within the appropriate geotechnical domain (i.e. 
pit sector of consistent geotechnical character). For this reason, spatial accuracy was not the controlling factor in the planning and execution of the fieldwork.

2. The density of the DTMs needed to be sufficiently high to provide enough points on each defect plane to accurately represent its orientation. With the typical minimum size of exposed planes targeted by the mapping being in the order of 200 to $300 \mathrm{~mm}$, the average point spacing of the DTMs targeted was between 60 and $100 \mathrm{~mm}$ (i.e. one third of the minimum feature size). This became the controlling factor in planning the fieldwork.

\subsubsection{Photography planning}

Based on the identified requirements for accuracy and DTM density (predominantly the latter) mentioned above, the photography of the quarry walls was planned with the help of the 'object distance' spreadsheet, which is provided as part of the 3DM Analyst software suite.

This spreadsheet allows the user to rapidly calculate a range of key parameters based on known or assumed requirements and constraints. For example, given the targeted minimum accuracy and distance to accessible camera station locations, the spreadsheet can be used to determine the required camera lens focal length and the optimal distance between camera stations. Conversely, if the camera station locations are fixed or inflexible (due to site access restrictions for example), the spreadsheet is used to calculate the maximum accuracy that could be achieved with a range of lens focal lengths.

In the following example shown from the current project (Figure 4), the known parameters of camera type, object distance (i.e. the distance from the camera stations to the subject rock face), and slope area dimensions (i.e. width and height of area to be photographed in a single model) were entered first. Then, the key variable parameters of lens focal length and base to distance ratio were varied until appropriate values of ground pixel size, nominal DTM density and overall accuracy were achieved. This process was followed for each section of the pit wall to be modelled and the results were used to plan actual camera station locations and photography specifications. 


\section{Object Distance Calculation Spreadsheet}

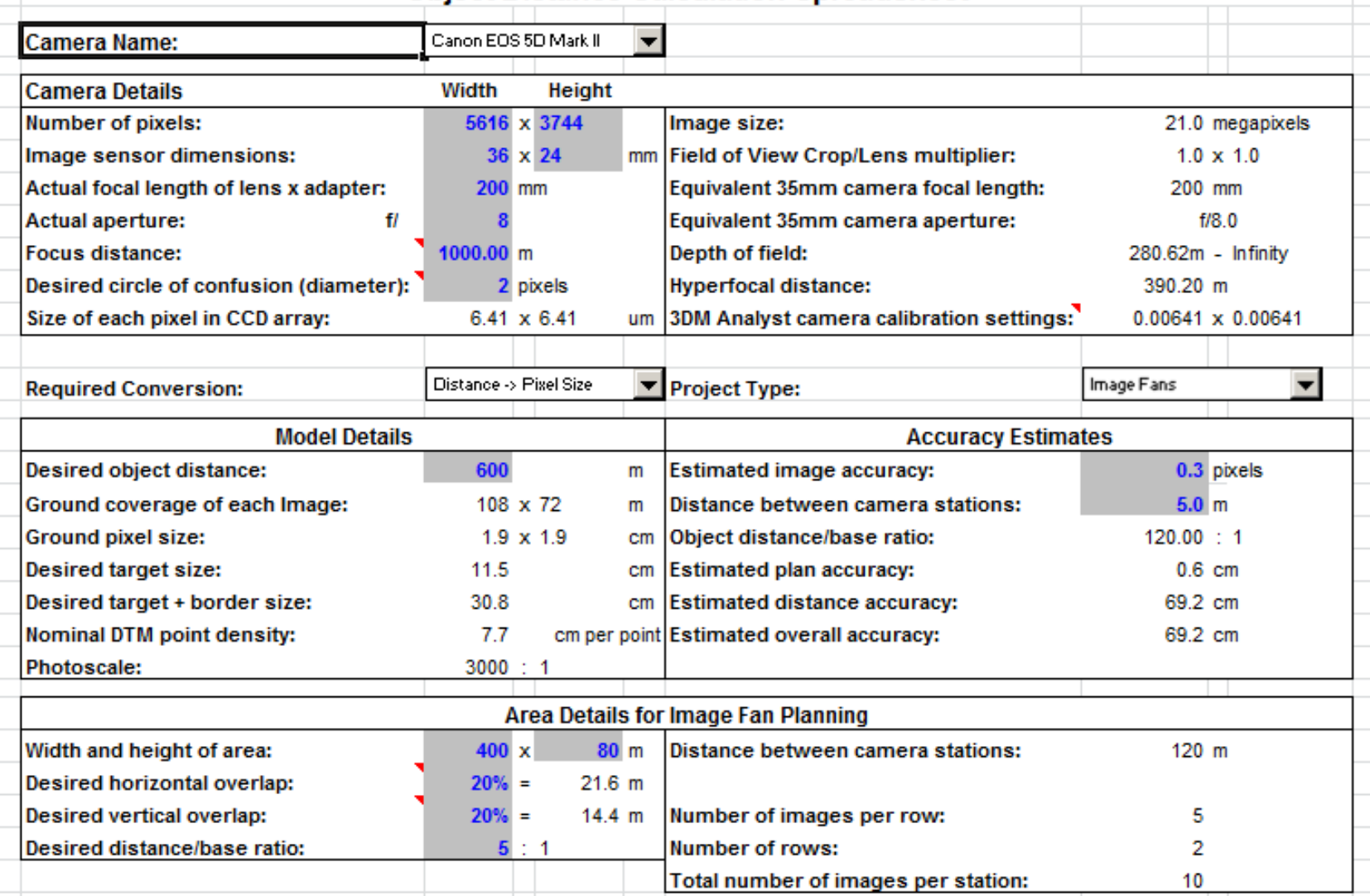

\section{Figure 4 Project example of photography planning undertaken using the object distance spread sheet (ADAM Technology, 2013)}

This planning process was undertaken prior to going to the site, based on a pit survey plan and an aerial photograph provided by the client. Once on site, some adjustments to the plan were required to suit actual site conditions on the day. Figure 5 shows the typical set-up of the DSLR camera mounted on a panoramic camera frame, which allows panning of the camera about the perspective centre of the camera lens. This enables accurate merging of individual images into photo mosaics, which provides substantial time savings in the fieldwork and data processing as compared with using stereo pairs of individual images. 


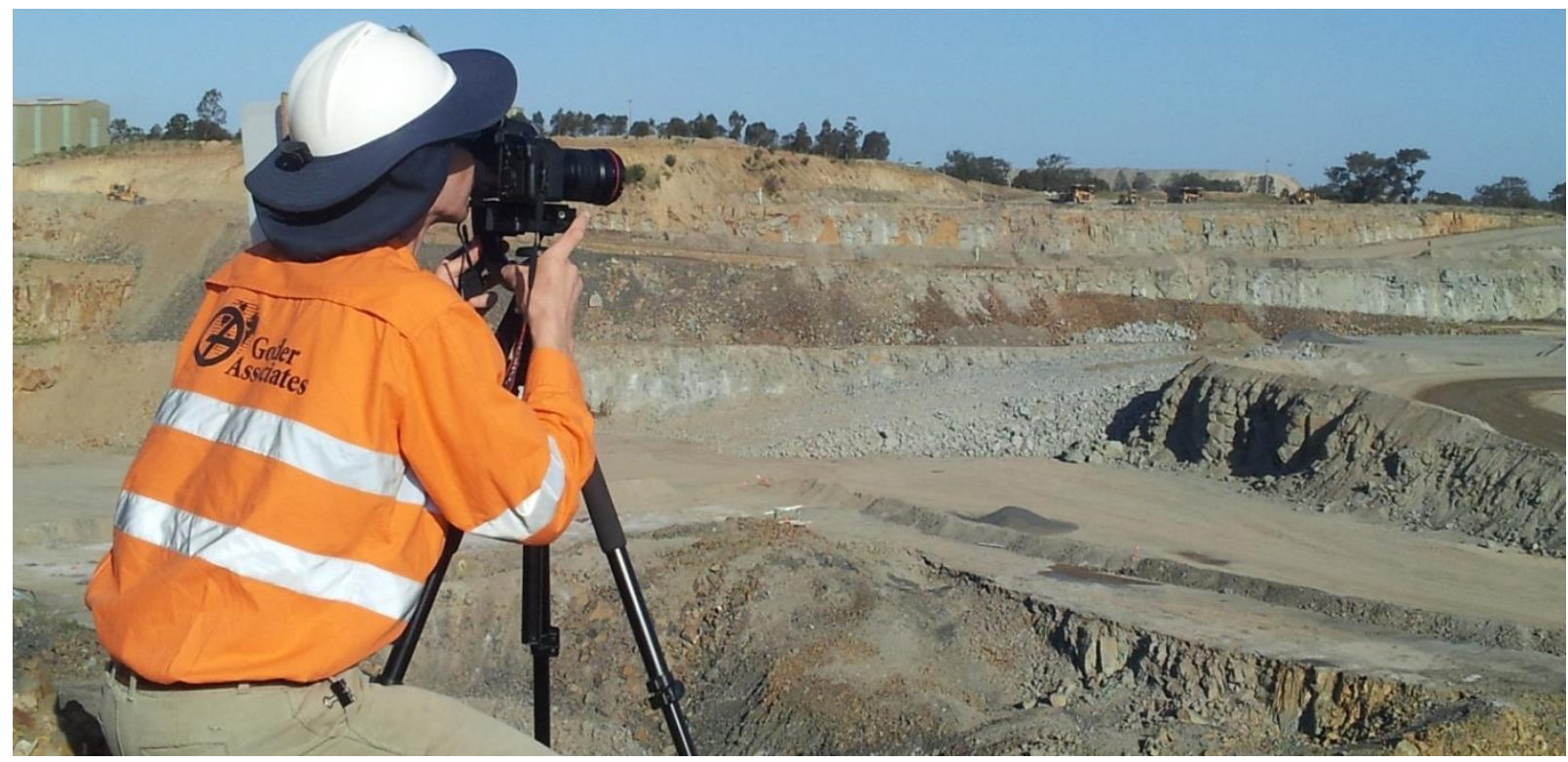

Figure 5 Typical set-up of DSLR camera mounted on panoramic camera frame and tripod used for the photography of the quarry pit walls

\subsubsection{Ground control survey}

An array of 17 ground control targets were established at strategic locations on the pit walls in the areas targeted by the mapping. The locations selected for the targets were designed to provide a reasonably even 3D spread across the scene being modelled. In this instance, the targets were then surveyed by a surveyor engaged by Holcim to a specified accuracy of $<=100 \mathrm{~mm}$, and the coordinates were provided to Golder for input at the processing stage. For other projects, Golder has acquired the ground control coordinates without the assistance of a surveyor, using a differential GPS unit.

The ground control targets comprised a white circle on a black background (Figure 6). The use of this type of circular target can significantly speed up the data processing as compared with informal markers (e.g. paint marks). This is because the 3DM Analyst software can automatically recognise the circular target with reduced used input (only three targets need to be manually digitised). However, other types of targets or even natural features can be used for ground control.

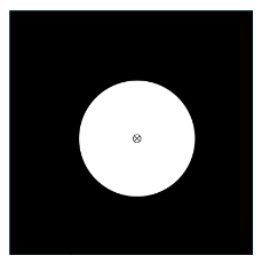

Figure 6 Typical ground control target configuration

\subsection{Data processing}

The input data for the processing stage comprised the digital photographs of the pit walls and the surveyed coordinates of the ground control targets. These were imported into the 3DM Analyst software and used to generate a series of DTMs covering the areas of the pit walls targeted for mapping.

The DTMs were then used to undertake mapping of the orientation, spacing, persistence and large scale waviness of defects exposed in the pit walls, using the geotechnical mapping tools within the software.

\subsection{Discontinuity mapping results}

The mapping results included more than 1,200 individual measurements of defect orientation, as well as a smaller number of measurements of spacing and persistence. The mapping aimed to obtain a 
representative sample of measurements of the main defect sets present in the rock mass. Selection of defects to be mapped was guided by the experience of the authors in recognising the prevailing jointing patterns, rather than following a 'blind' statistical approach wherein every defect exposed in an area or along a scanline is mapped. This experience-based approach was considered to be appropriate for use in a preliminary phase study such as this one.

\subsection{Defect shear strength and large scale waviness}

The undulations and asperities on a natural joint surface have a significant influence on its shear behaviour. Generally, this surface roughness increases the shear strength of the surface, and this strength increase is extremely important in terms of the stability of excavations in rock (Hoek, 2007).

Patton (1966) demonstrated this influence by means of an experiment in which he carried out shear tests on 'saw-tooth' specimens. Shear displacement in these specimens occurs as a result of the surfaces moving up the inclined faces, causing dilation of the specimen.

The shear strength of Patton's saw-tooth specimens can be represented by:

$$
\tau=\sigma_{n} \tan \left(\phi_{b}+i\right)
$$

Where:

$$
\begin{aligned}
& \phi_{b}=\text { the basic friction angle of the surface. } \\
& i \quad=\text { the angle of the saw-tooth face. }
\end{aligned}
$$

In a natural defect, the i-angle can be considered as the angular difference between the overall dip of the defect and the dip of the undulations in the defect. The important areas to consider for stability assessments are the 'up-ramp' sides of the undulations, were the moving block must move up and over to continue sliding.

This very simple approach to assessing the effect of defect waviness on shear strength is applicable only in situations of low normal stress, since it does not reflect the reality that changes in shear strength with increasing normal stress are gradual rather than abrupt (Hoek, 2007).

However, for the current purpose of making a preliminary assessment of shear strength increase in defects at shallow depth in a pit wall, the authors consider this approach to be appropriate. A more robust method, such as Barton $(1973,1976)$, would be recommended for a more advanced study.

Observations of the rock defects in the drill core and exposed in the batters of the quarry indicate that they are generally quite smooth, and often contain low shear strength infill materials such as chlorite. These observations, which were made directly in the outcrop and drill core, i.e. not remotely with photogrammetry, were indicative of low defect shear strengths. The increased shear strength imparted by the large scale waviness of the defects was therefore identified as being important to batter stability and the geotechnical design. A quantitative assessment of the waviness therefore formed an important part of the study.

In order to obtain quantitative measurements of large scale waviness, a number of high resolution DTMs were produced of selected persistent defect surfaces exposed in the pit walls. Figures 7 and 8 show one example of a joint surface modelled in this way. The exposed plane shown (outlined by the red dashed polygon in Figure 7) was approximately $9 \mathrm{~m}$ wide by $17 \mathrm{~m}$ high. The typical DTM point spacing achieved on the surface (Figure 8) ranged from about 20 to $100 \mathrm{~mm}$, with a total of 112,218 measured points across the full area of the plane. 


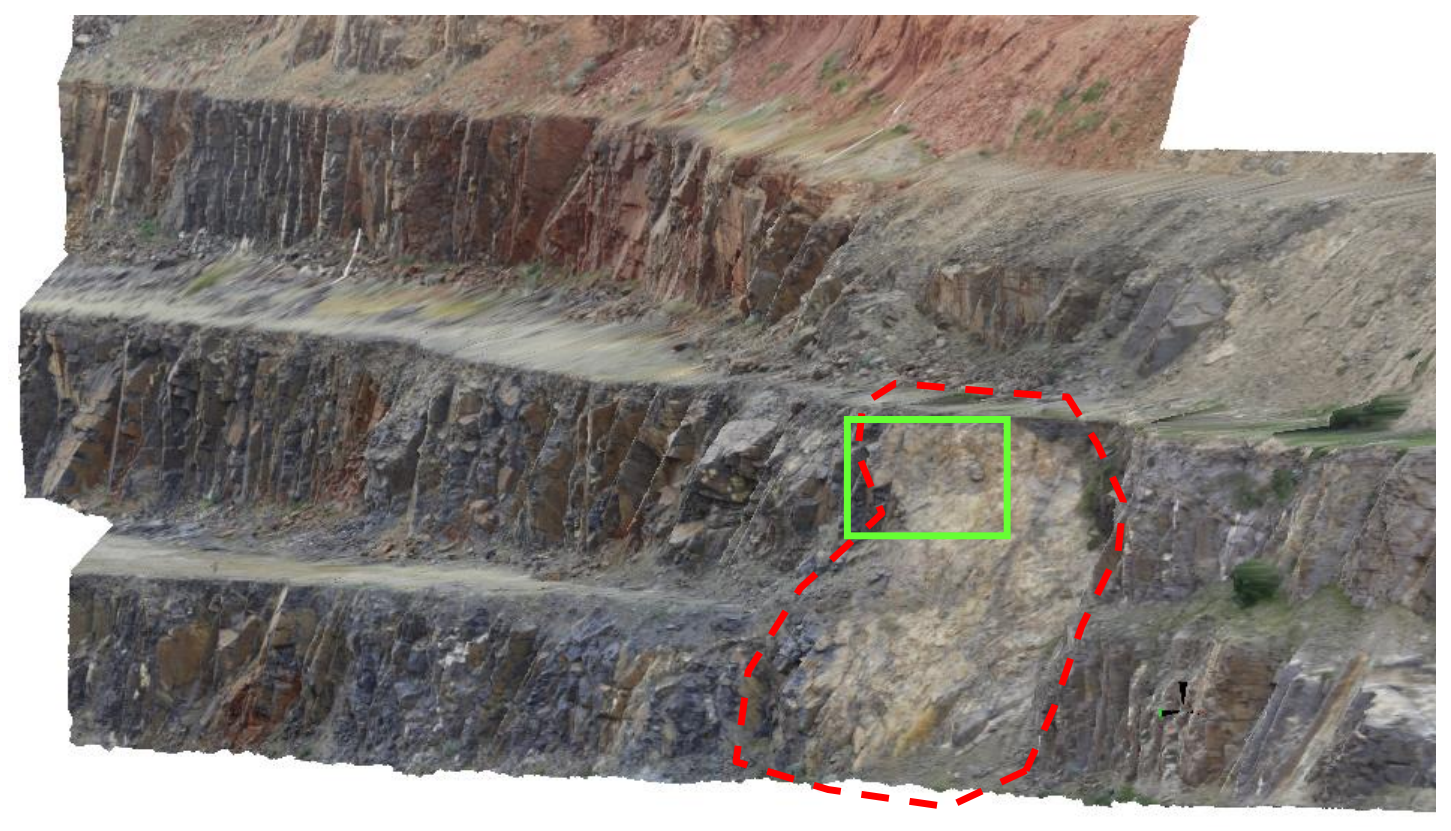

Figure 7 Oblique view of a typical DTM generated for the study using photogrammetry, rendered with the image texture. The dashed polygon outlines an exposed joint surface assessed for large scale waviness. The small rectangle outlines a $3 \times 5 \mathrm{~m}$ section of the joint surface, enlarged in Figure 8

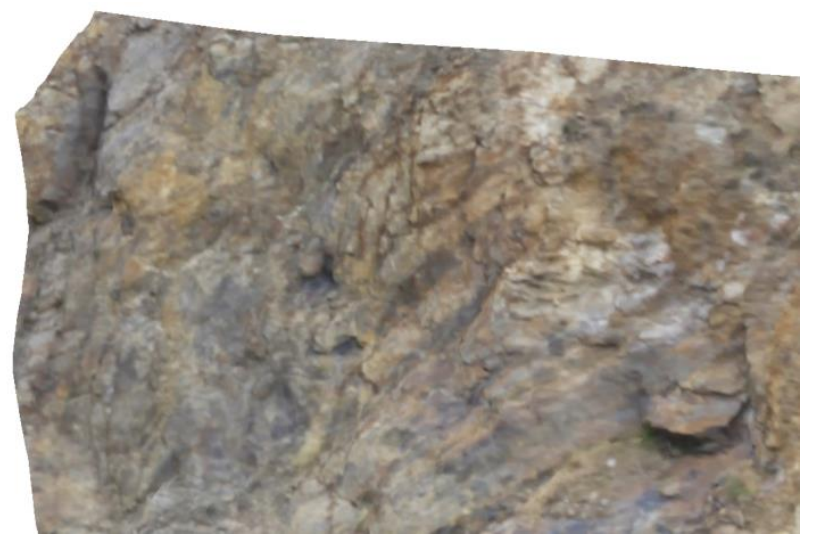

(a)

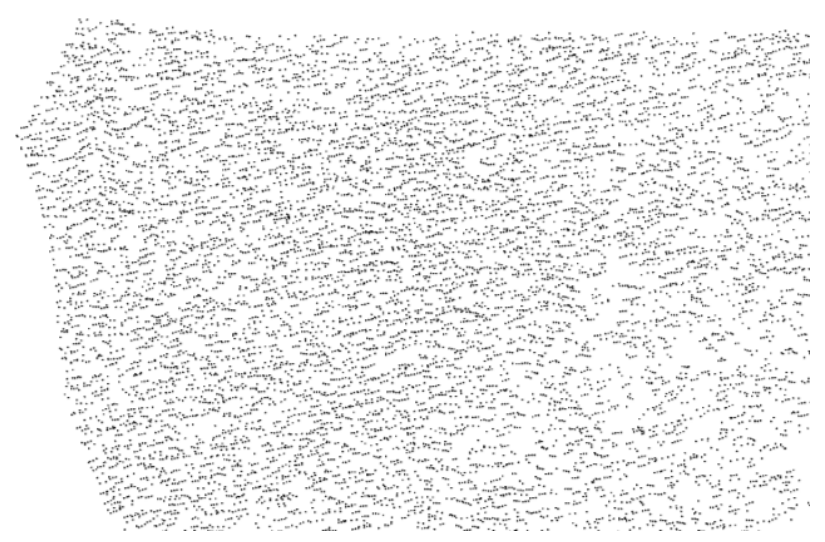

(b)

Figure 8 (a) Close-up view of a $3 \times 5$ m section of the joint surface DTM shown in Figure 7; (b) same view as (a), but showing the density of the 'point cloud' making up the DTM (typical point spacing 20 to $100 \mathrm{~mm}$ )

The DTMs of the defect surfaces modelled were exported from 3DM Analyst to Vulcan (Maptek, 2013b) for further analysis. A series of cross sections were cut through the DTMs (Figure 9).

The cross sections were used to measure i-angle of the large scale undulations of the defects, using simple ruler and protractor methods. Observations made of existing failure surfaces at the site indicated that simple sliding movement was occurring down the dip of the defects, over the asperities, so the influence of intact rock failure in the asperities was not seen as a significant factor.

I-angles were measured on the 'up-ramp' side of the larger undulations in five cross sections, with between three and six of the largest undulations measured on each cross section. A comparison of an example cross-section for each of the major defect sets showed similarities in the large scale waviness between defect sets. 


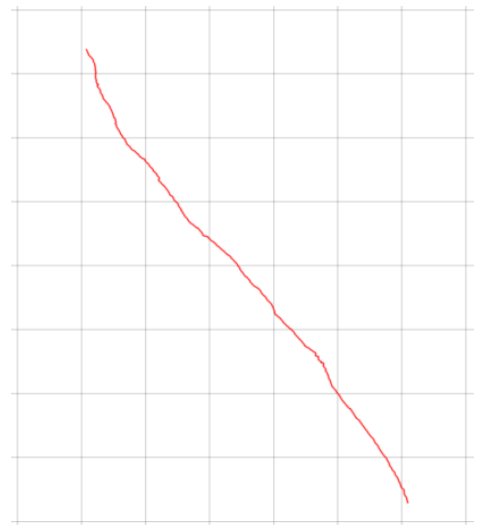

Figure 9 Example of a cross section through the joint surface DTM shown in Figures 7 and 8 . The grid squares shown are $2 \times 2 \mathrm{~m}$

The i-angles measured ranged between 2 and $15^{\circ}$. A relatively conservative figure of $5^{\circ}$ was adopted as the i-angle for addition to the small scale (i.e. drill core scale) defect angle of friction in the kinematic analysis.

\section{$5 \quad$ Geotechnical drilling}

Two boreholes were drilled into the western end of the northern face prior to the study commencing for resource assessment purposes. The core was observed on site, with the general defect and rocks strength observations of the core used to assist in the overall assessment of the rock mass behind the northern wall. One borehole was drilled at the top of the pit wall, approximately $20 \mathrm{~m}$ back from the crest and the other borehole was drilled into the first bench down from the top of the wall, approximately in the centre of the bench. The boreholes were inclined at an angle of $60^{\circ}$ and were oriented approximately parallel with the pit wall orientation. Hence, defects dipping steeply out of the pit walls (i.e. sub-parallel to the boreholes) are likely to have been under-sampled by the boreholes. This fact underscored the importance of the mapping undertaken.

The boreholes produced $\mathrm{N}$-sized $(53 \mathrm{~mm})$ core. The core was not oriented, and therefore the dip and orientation of the defects could not be used for defect modelling in the rock mass. However, general observations of the frequency and surface characteristics of the defects were made and used to assist in a qualitative assessment of the angle of friction.

The defects were found to be typically very planar, showing very little small scale waviness. Defects of all orientations in the core showed this characteristic. Defect infill materials were generally low shear strength, fine grained minerals such as chlorite. Some iron staining of defects was present in the core up to approximately $40 \mathrm{~m}$ below the natural surface level; however this did not appear to have increased the small scale roughness of the defects significantly.

The chosen small scale friction angle for the defects in the pit walls was $25^{\circ}$. The selection was made based on lower bound estimates presented in literature of hard, smooth, fine grained metamorphic rocks.

\section{$6 \quad$ Stability analyses}

Based on observations of the pit walls, three geotechnical domains were identified for kinematic analysis. The northern wall was split into eastern and western domains and the western wall was treated separately.

The defect orientation data obtained from the photogrammetric mapping was input into the Rocscience software program DIPS (Rocscience Inc., 2013a) and major defect sets were interpreted from the stereograph plot produced. A kinematic analysis was undertaken for each geotechnical domain. A defect friction angle of $30^{\circ}$ was used, comprising a small scale friction angle of $25^{\circ}$ plus a large scale waviness $i$-angle of $5^{\circ}$. Planar failure, wedge failure and toppling failure mechanisms were analysed. 
Using the major defect sets identified, an analysis was carried out of the size of potential wedge failures in the benches using the Rocscience software program Swedge (Rocscience Inc., 2013b). Figure 10 shows example results from the kinematic analysis. Figures 11 and 12 show the main defect features in the western and northern walls.

Optimal slope angles, both for the batters and the overall pit slopes were determined based on the possible failure mechanisms. Consideration was also given to the final rehabilitation pit slope design in the approved work plan, which stipulated certain bench widths and heights based on the depth within the pit. The final recommended slope design for the pit walls to the current depth of $60 \mathrm{~m}$ took into account both the need to satisfy the required bench and batter dimensions as well as safe long term batter slope angles.

The existing failures observed in the pit corroborated the chosen final angle of friction for the defects, with large scale planar failures observed on defects dipping as low as between 30 and $35^{\circ}$.

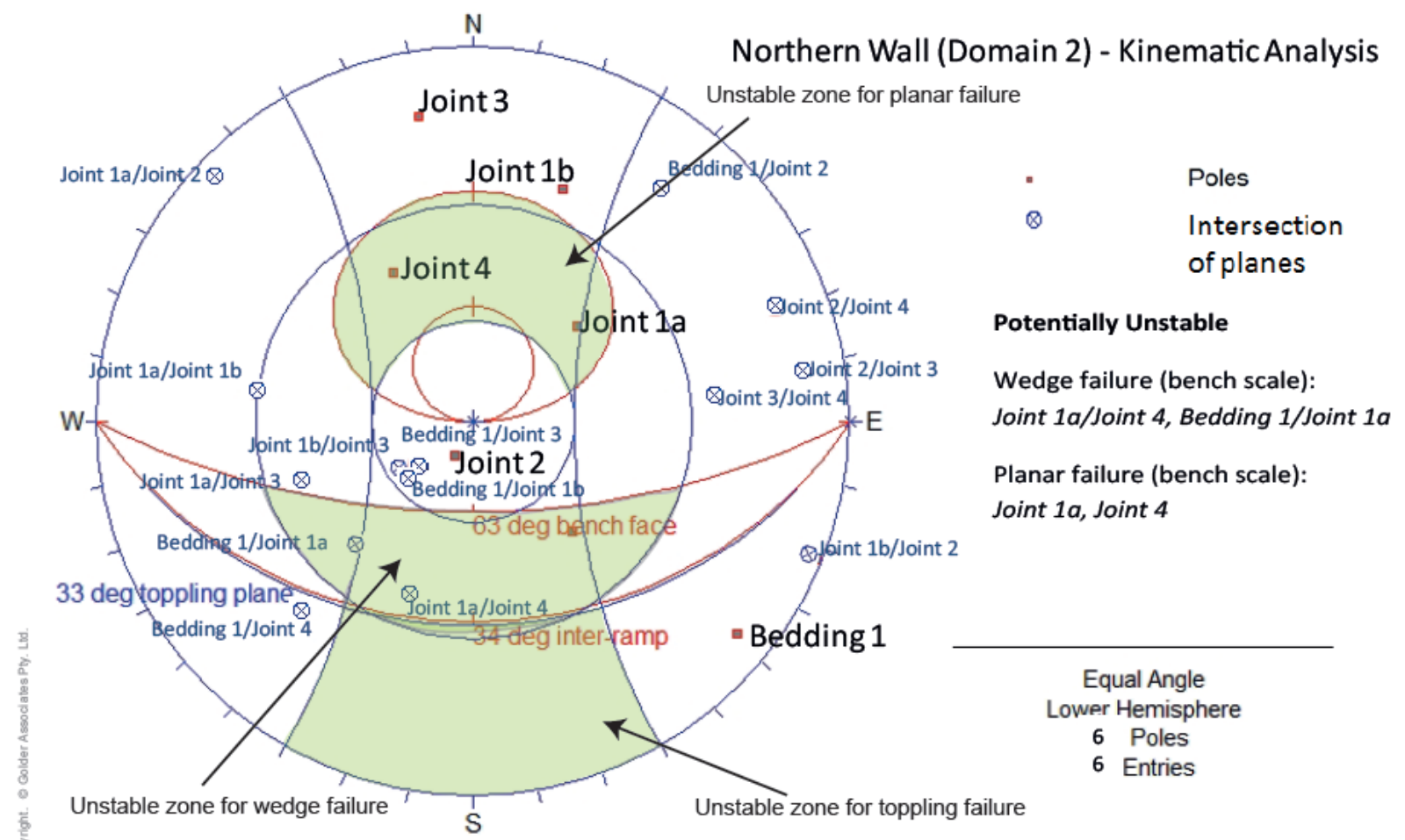

Figure 10 Example results from DIPS analysis

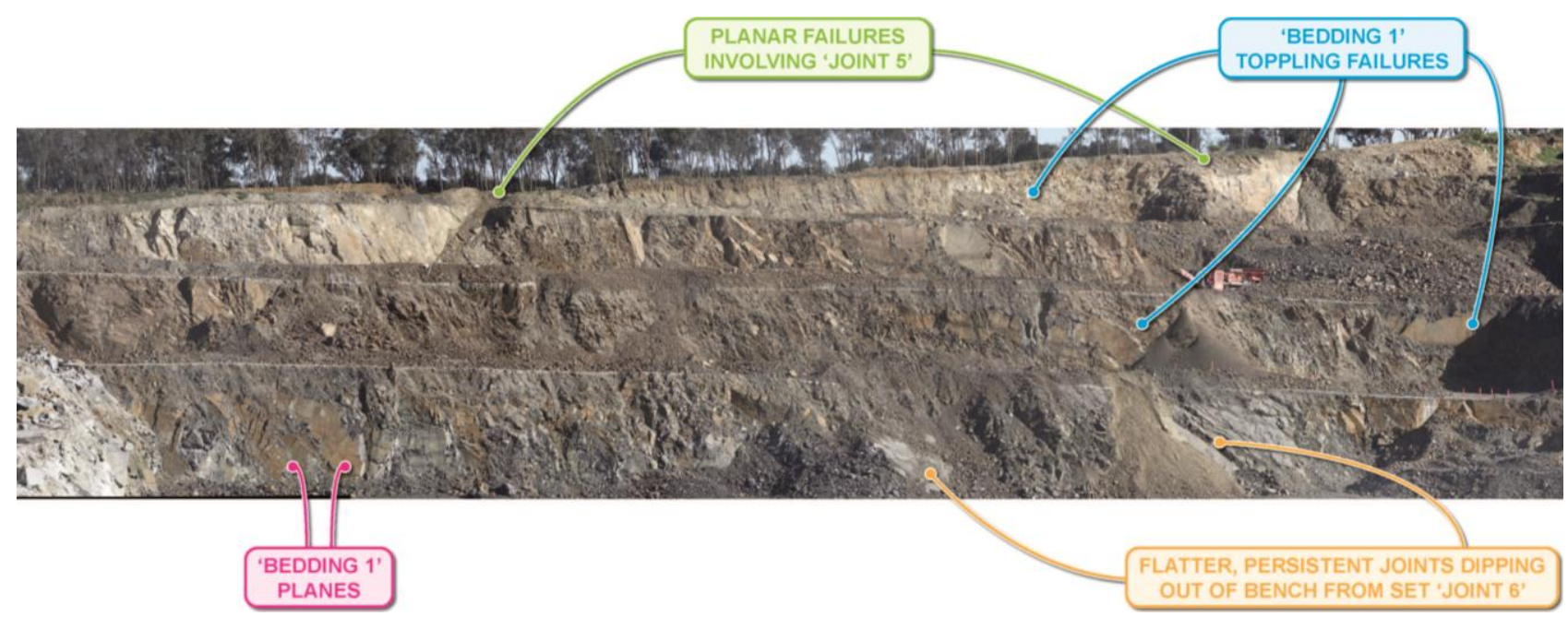

Figure 11 Western wall panorama showing main defect features 


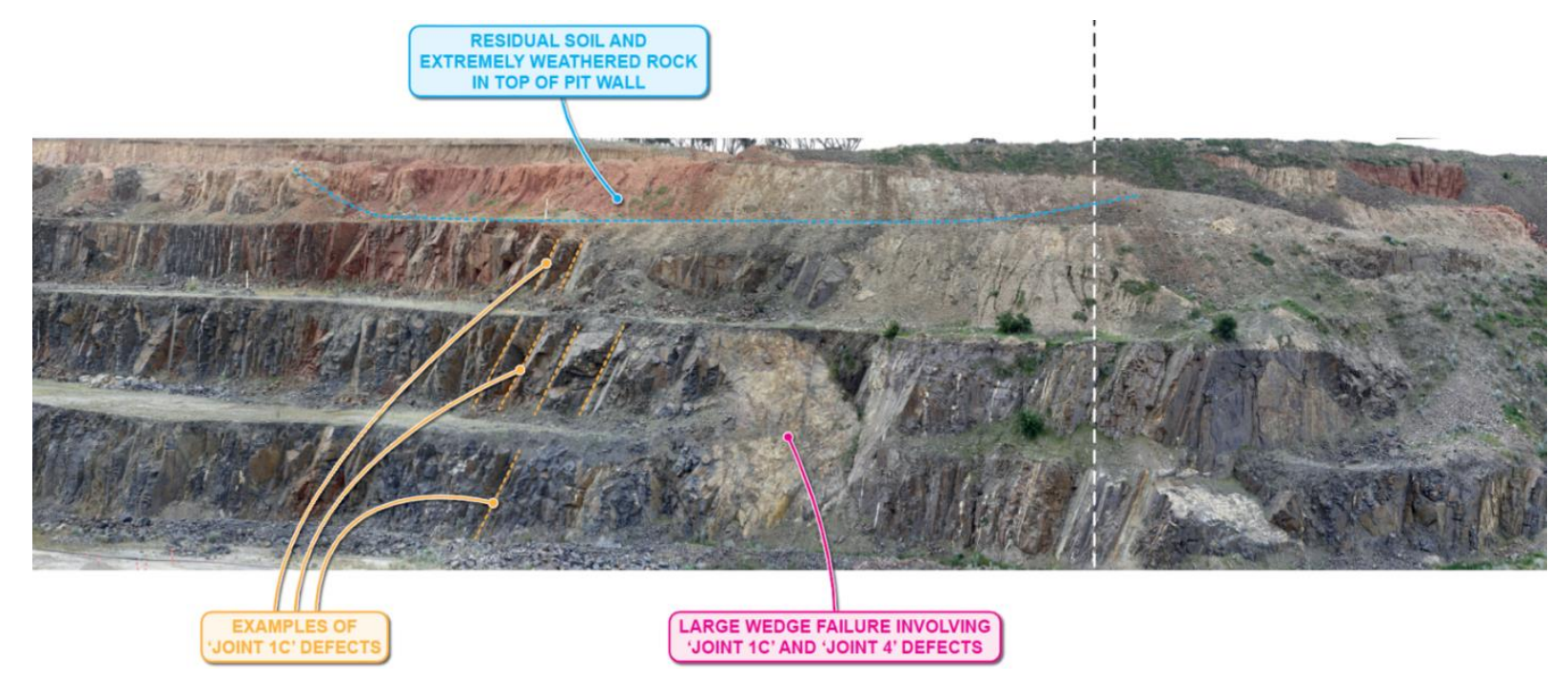

Figure 12 Northern wall (eastern end) panorama showing main defect features

\section{$7 \quad$ Future studies for design optimisation}

The studies undertaken to date, as described in this paper, have provided a basic understanding of the rock mass conditions at the quarry and have identified the key potential failure mechanisms likely to control the stability of current and future pit walls. They have also provided a good indication of areas where the pit design may be able to be further optimised to increase resource recovery from the pit. The requirement to consider long term stability and regulatory rehabilitation design parameters in the design has been satisfied.

However, further studies will be required in the future to allow the development of a robust set of geotechnical pit design parameters. The current study has been restricted to the observable pit walls at this stage. With Holcim's plans for deepening of the pit, an assessment of the geotechnical conditions at depth is prudent, particularly if large, persistent defects similar to those observed in the existing pit walls are present.

Future geotechnical work for the pit design at depth would likely include:

- Drilling of oriented geotechnical boreholes to the proposed depth of the pit, particularly behind the northern and western walls.

- A laboratory testing program for measurement of unconfined compressive strength (UCS) of the intact rock as well as defect shear strength testing.

- Conventional geotechnical mapping of selected (safely accessible) batters in the quarry to obtain further information about small scale roughness and infill material types.

- More detailed mapping of the photogrammetric DTMs to obtain additional measurements of defect orientation, spacing, persistence and large scale waviness.

- Detailed mapping, using the DTMs, of in situ block sizes and variations in rock mass quality in the pit walls.

\section{Conclusions}

The use of digital photogrammetry to undertake remote geotechnical mapping at the Oaklands Junction quarry has provided a number of benefits to the current study as compared with conventional geotechnical mapping methods. These have included increased mapping coverage, a larger set of high quality geotechnical data and improved safety through elimination of exposure of mapping personnel to rockfall hazards. 
Digital photogrammetry is an adaptable and versatile tool, with a wide range of applications in different industry sectors and technical disciplines. For the present application, the photogrammetry based systems used had a number of advantages over alternative, laser-based systems. These included: the ability to georeference the data using a small number of known points; greater flexibility in range and location of the data collection station; greater accuracy at large distances from the subject slope; and lower establishment costs for purchase of the hardware and software.

When appropriately applied to the task of geotechnical mapping of jointed rock masses, modern digital photogrammetry tools can provide quality data sets in relation defect orientation, persistence, spacing, large scale waviness and 'real world' location; block size; and geotechnical character and spatial relationships of large scale geological structures. A key limitation of long-range digital photogrammetry for geotechnical mapping is that it cannot provide information about infill material type, infill thickness (or aperture), joint wall strength, or small scale roughness. However, small scale roughness can be measured by using close-range photogrammetry techniques.

The results of the large scale defect waviness measurements made for the current study using photogrammetry provided quantitative justification to increase the large scale friction angle adopted for the subsequent stability analyses by $5^{\circ}$. This has the potential to lead to increased overall pit wall angles being recommended following future design optimisation studies.

The studies undertaken to date have provided a basic understanding of the rock mass conditions, identified the key potential failure mechanisms, and identified areas where the pit design may be able to be further optimised. Further studies will be required in the future to develop a robust set of geotechnical design parameters. Data collection for these studies may include further drilling, laboratory testing and conventional geotechnical mapping. However, before embarking on these relatively costly tasks, a great deal more geotechnical information can be obtained from further office-based analysis of the photogrammetry DTMs that are already available. This could include further mapping of defect orientation, spacing, persistence and large scale waviness, as well as detailed assessment of in situ block size and rock mass quality.

\section{Acknowledgement}

The Authors thank Damon Bird, national reserves manager / principal geologist, Holcim (Australia) Pty Ltd for permission to publish this paper.

\section{References}

3G Software and Measurement (2013) 3G Shape Metrix, http://www.3gsm.at. ADAM Technology (2010) 3DM Analyst Mine Mapping Suite User Guide, 378 p.

ADAM Technology (2013) 3DM Analyst Mine Mapping Suite, http://www.adamtech.com.au/3dm/Analyst.html.

Barton, N. (1973) Review of a new shear strength criterion for rock joints, Engineering Geology, Elsevier, Amsterdam, Vol. 7, pp. 287-332. Also published in (1974) Norwegian Geotechnical Institute, Oslo, Vol. 105.

Barton, N. (1976) The shear strength of rock and rock joints, International Journal of Rock Mechanics and Mineral Science and Geomechanics Abstracts, Elsevier, Amsterdam, Vol. 13, No. 9, pp. 255-279. Also published in Norwegian Geotechnical Institute (1978), Oslo, Vol. 119.

CEA Mining Australia (2013) Sirovision digital photogrammetry system, http://sirovision.com/.

Day, N. (2010) Terrestrial Photogrammetry as an Alternative to Laser Scanning, Geomatics World, PV Publications, March/April 2010, pp. 32-34.

Geological Survey of Victoria (2013) viewed 6 August 2013, http://mapshare2.dse.vic.gov.au/MapShare2EXT/imf.jsp?site=geovic.

Hoek, E. (2007) Practical Rock Engineering, Rocscience, 237 p, viewed 15 July 2013, http://www.rocscience.com/hoek/corner/ Practical_Rock_Engineering.pdf.

Maptek (2013a) I-Site, http://www.maptek.com/products/i-site/.

Maptek (2013b) Vulcan, http://www.maptek.com/products/vulcan/.

Patton, F.D. (1966) Multiple modes of shear failure in rock, in Proceedings First Congress of the International Society of Rock Mechanics, 25 September - 1 October 1966, Lisbon, Portugal, pp. 509-513.

Rocscience Inc. (2013a) DIPS, http://www.rocscience.com/products/1/Dips.

Rocscience Inc. (2013b) Swedge, http://www.rocscience.com/products/1/Dips.

Spring, A.P. (2012) Digital photogrammetry and ADAM technologies, Geolnformatics, CMedia, Vol. 15, June 2012, pp. $18-21$. 